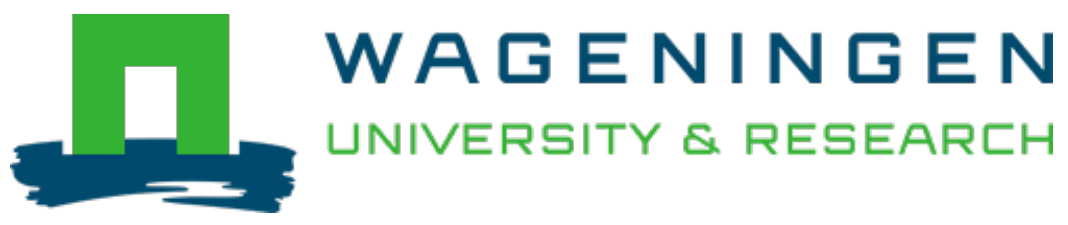

\title{
The contribution of semi-natural habitats to biological control is dependent on sentinel prey type
}

\author{
Journal of Applied Ecology \\ McHugh, Niamh M.; Moreby, Steve; Lof, Marjolein E.; Werf, Wopke; Holland, John M. \\ https://doi.org/10.1111/1365-2664.13596
}

This publication is made publicly available in the institutional repository of Wageningen University and Research, under the terms of article $25 \mathrm{fa}$ of the Dutch Copyright Act, also known as the Amendment Taverne. This has been done with explicit consent by the author.

Article 25 fa states that the author of a short scientific work funded either wholly or partially by Dutch public funds is entitled to make that work publicly available for no consideration following a reasonable period of time after the work was first published, provided that clear reference is made to the source of the first publication of the work.

This publication is distributed under The Association of Universities in the Netherlands (VSNU) 'Article $25 \mathrm{fa}$ implementation' project. In this project research outputs of researchers employed by Dutch Universities that comply with the legal requirements of Article $25 \mathrm{fa}$ of the Dutch Copyright Act are distributed online and free of cost or other barriers in institutional repositories. Research outputs are distributed six months after their first online publication in the original published version and with proper attribution to the source of the original publication.

You are permitted to download and use the publication for personal purposes. All rights remain with the author(s) and / or copyright owner(s) of this work. Any use of the publication or parts of it other than authorised under article $25 \mathrm{fa}$ of the Dutch Copyright act is prohibited. Wageningen University \& Research and the author(s) of this publication shall not be held responsible or liable for any damages resulting from your (re)use of this publication.

For questions regarding the public availability of this publication please contact openscience.library@wur.nl 


\title{
The contribution of semi-natural habitats to biological control is dependent on sentinel prey type
}

\author{
Niamh M. McHugh ${ }^{1}$ (D) | Steve Moreby ${ }^{1}$ | Marjolein E. Lof ${ }^{2,3}$ | Wopke Van der Werf ${ }^{2}$ | \\ John M. Holland ${ }^{1}$
}

${ }^{1}$ Farmland Ecology Unit, Game and Wildlife Conservation Trust, Fordingbridge, UK

${ }^{2}$ Centre for Crop Systems Analysis, Wageningen University, Wageningen, The Netherlands

${ }^{3}$ Environmental Systems Analysis Group, Wageningen University, Wageningen, The Netherlands

\section{Correspondence}

Niamh M. McHugh

Email: nmchugh@gwct.org.uk

Funding information

Seventh Framework Programme,

Grant/Award Number: 311879

Handling Editor: Juan Corley

\section{Abstract}

1. It is widely recognized that landscape factors affect the biological control of weed seeds and insect pests in arable crops, but landscape effects have been found to be inconsistent between studies.

2. Here, we compare six different types of sentinels (surrogate prey that was either live insects or seeds) to measure the effects of semi-natural habitats at field to landscape scales on levels of biological control in winter wheat in the UK. Sentinels were located in fields adjacent to three boundary types: grassy margin, hedgerows or woodland to study the local scale effects and in landscapes of varying heterogeneity in study areas of $1-\mathrm{km}$ radius.

3. Overall, mean levels of predation were higher for most insect prey $(60.8 \%)$ located on the ground compared to the crop (12.2\%) and was lower for seeds (5.8\%). Predation of sentinels on the ground was attributed to generalist predators. Semi-natural habitats had both positive and negative effects at field and landscape scales, but the response varied with the sentinel type. Herbaceous linear semi-natural habitats had positive effects at local scales for Calliphora vomitoria and Sitobion avenae sentinels and provide evidence that farmers can introduce linear herbaceous features to benefit biological control. In contrast, our distanceweighted kernel models identified a positive relationship between woody habitats and the predation of $\boldsymbol{C}$. vomitoria and Chenopodium album. Natural aphid infestations were lower in landscapes with more semi-natural habitat.

4. Synthesis and applications. Sentinels may be sensitive enough to detect variation in levels of biological control influenced by semi-natural habitats, but this study confirms that landscape effects differ for different types of sentinel prey. This implies that it may not be possible to categorize landscapes as pest suppressive using a single sentinel type. Future studies should therefore consider using multiple sentinels to give a better perspective on predation intensity. The resulting recommendations for farm management include planting woodland adjacent wheat fields infested with seed predators and positioning herbaceous linear habitats adjacent wheat fields infested with Sitobion avenae, particularly if fields are bordered by woody liner habitats due to their association with decreased S. avenae predation. 


\section{KEYWORDS}

agroecology, aphids, biological control, ecosystem services, landscape ecology, semi-natural habitat, sentinel, surrogate prey

\section{1 | INTRODUCTION}

Farmed landscapes typically comprise fields interspersed with patches or strips of semi-natural habitat $(\mathrm{SNH})$ including woodland, grassland or herbaceous plants. These are usually managed to some extent, either for their resources (e.g. woodland) or to prevent field encroachment. SNHs provide resources that can be utilized by natural enemies, for example, food, shelter and hibernation habitat, and it is thought that landscape management may enhance the function of SNH such that biocontrol functions in agricultural landscapes are strengthened (Holland et al., 2016). Since the late 1990s, the value of SNHs to support pest natural enemies has been intensively studied (Griffiths, Holland, Bailey, \& Thomas, 2008). The most widely investigated habitats are woodland, hedgerows and grassland as these are the predominant habitats in agricultural areas (Holland et al., 2017). Natural enemies may migrate from the SNH into the adjacent crops after winter or later in the season while the more mobile species (e.g. hoverflies, ladybirds) may disperse and colonize crops over larger distances, sometimes alternating betwen $\mathrm{SNH}$ and crops throughout the crop growing period (Thorbek \& Topping, 2005). Consequently, the level of natural enemies within any field is a combination of local and landscape scale effects (Tscharntke et al., 2012). Likewise, pest levels reflect local and landscape influences, as pests may also make use of SNH during the time when crops are not available, the levels being further mitigated by natural enemies (Bianchi, Booij, \& Tscharntke, 2006).

Despite the hypothesized contribution of natural enemies to pest control, there are few examples of studies which measure this. Of 142 publications that investigated the ecosystem service 'pest control', only $22 \%$ reported on the impact on pests (Holland et al., 2017). This may be for logistical or financial restrictions imposed on studies, insufficient pests during the study or perceived difficulties in isolating the impact of natural enemies compared to other factors that can influence pest levels. One approach which overcomes these restrictions is to use surrogate prey items (sentinel systems) that aim to represent actual pests, but whose abundance and location can be controlled within the field. A further advantage is that if standardized approaches are developed they may be replicated between studies allowing for standardized data to be generated. A number of sentinel systems have been previously developed and tested to measure invertebrate (Chisholm, Gardiner, Moon, \& Crowder, 2014) and especially weed seed predation (Westerman, Hofman, Vet, \& van der Werf, 2003), but the effectiveness of different methods has rarely been evaluated (but see Zou et al., 2017) nor has their ability to detect local, landscape or distance-weighted effects of $\mathrm{SNH}$.

Starting in 2013, the QuESSA project (http://www.quessa.eu/) designed and used a range of sentinel systems to test whether the type and proportion of SNH from field to landscape scales was influencing levels of biological control across Europe (Holland et al., 2014). Here we report on the findings for winter wheat based upon up to 2 years data, for six different sentinel systems applied in the UK. The main invertebrate pests of winter wheat during summer in the UK are dipteran pests (e.g. Sitodiplosis mosellana, family Cecidomyiidae) and cereal aphids (e.g. Sitobion avenae, Aphididae). Pest natural enemies are most likely to exert control on diperteran pests when pupae are within the soil, after pupation while they move through the soil to the surface, when adults are laying their eggs and when larvae complete feeding and travel to the soil surface to pupate (Holland \& Thomas, 2000). For cereal aphids, control occurs when feeding on the crop but also a large proportion of aphids regularly fall to the ground and are consequently vulnerable to ground predators (Winder, 1990). Weed seeds that are produced by weedy plants that escape herbicide control can contribute to the seed bank but are consumed by natural enemies, especially carabid beetles (Trichard, Alignier, Biju-Duval, \& Petit, 2013; Westerman et al., 2003). They are also consumed by rodents, molluscs, earthworms and birds (Cardina \& Sparrow, 1996; Cromar, Murphy, \& Swanton, 1999). Therefore, both epigeal and crop active invertebrate natural enemies are important in the control of pests in cereal crops.

When studying landscapes for their biocontrol potential, it is important to take into account that enemies of one pest may not be effective against another pest, while habitats that favour a particular natural enemy may not be utilized by another one. Therefore, landscape effects could depend on the prey. Then, assessing biocontrol potential of landscapes can be helped using a suite of potential prey rather than a single prey. Here, we test whether it is indeed necessary to account for an effect of prey type on the effectiveness of landscapes in providing biocontrol services.

In this study, four sentinels representing insect prey, two representing weed seeds as well as naturally occuring cereal aphids were evaluated to determine whether they are capable of detecting the effects of SNH on biological control at local and landscape scales. Additionally, we examine relationships with $\mathrm{SNH}$ using distance weighting kernel models to assess at which distance SNH in the landscape are affecting biocontrol. If different enemies, with different dispersal abilities, control different pest taxa and different habitats support those enemies, it should be expected that such distance functions differ between pest taxa. We test this hypothesis. 


\section{2 | MATERIALS AND METHODS}

\section{1 | Study area}

The study was conducted in 18 focal fields of winter wheat per year surrounded by a 1-km radius landscape circle in the South East and South West regions (counties Dorset and Hampshire) of the UK in 2014 and 2015 (Figure 1). A 1-km radius was used because this was the distance over which many previous studies had detected an influence on biocontrol in cereal crops (e.g. Rusch et al., 2016). The area has a temperate climate, summers are warm and humid (Kottek, Grieser, Beck, Rudolf, \& Rubel, 2006).

Due to crop rotation, focal fields sown with winter wheat in 2014 were put into a different crop in 2015 which prevented the use of the same focal fields and their surrounding landscape circles in 2015. Between years, landscape circles were, however, selected to be close together and are defined as landscape circle pairs. The central point of landscape circle pairs was separated by a distance of $90 \mathrm{~m}$ to $3 \mathrm{~km}$ (M $1.15 \pm 0.05 \mathrm{~km}$ ).

\section{2 | Sampling design}

A standardized QuESSA protocol was followed that examined the impact of three different boundary types (local effect) on sentinel predation. From the 18 focal fields studied each year, six had a field boundary for each of three categories: (a) herbaceous strip between fields (control), (b) woody linear habitat (hedgerow) or (c) woody areal habitat (woodland; Table S1). Within each field, sentinels were placed at 2, 25, 48 and $71 \mathrm{~m}$ from the adjacent SNH, along two transects $10 \mathrm{~m}$ apart (Figure S1). To minimize the influence of the other field boundaries on transects, the distance between the end of the transects and non-focal field boundaries had to be at least 1.25 times the length of the transect (i.e. $88.75 \mathrm{~m}$ ).

All SNHs within a 1-km radius of the transect centres were digitized in Arc GIS V.10.5 (ESRI, 2011), using the Lambert Azimuthal Equal Area geo-referencing system. SNH present in landscape circles were mapped using the Customer Land Database (CLAD) and in-field observations, SNH were then categorized as herbaceous linear, herbaceous areal, woody linear, woody areal or fallow (land which has been plowed and left unseeded for at least one season). Areal habitats were defined as having a minimum width of $25 \mathrm{~m}$, whereas linear habitats were between 1.5 and $25 \mathrm{~m}$ wide, both areal and linear habitats were defined as having a minimum length of $50 \mathrm{~m}$ and minimum surface area of $75 \mathrm{~m}^{2}$. Herbaceous habitats comprised $<30 \%$ shrub/tree cover and include sown habitats, while woody habitats had $>30 \%$ shrub/tree cover. Total SNH was calculated as the sum of these habitats.

\section{3 | Sentinel sampling}

The sentinels were deployed on two occasions in June/July 2014 and 2015. They comprised Calliphora vomitoria larvae (Diptera: Calliphoridae), Ephestia kuehniella eggs (Lepidoptera: Pyralidae), Drosophila melanogaster pupae (Diptera: Drosophilidae, one round in 2014 only), Poa trivialis seeds (Poaceae) and Chenopodium album seeds (Amaranthaceae), which were all located on the ground, and S. avenae adults which were artificially attached to the crop (see below). Calliphora vomitoria larvae were pinned live to strips of 6-mm thick plastazote $(1 \times 10 \mathrm{~cm}), 10$ per strip. To mimic Lepidoptera egg-laying, E. kuehniella egg masses were exposed on four corners $(0.25 \times 0.25 \mathrm{~cm}$ each) of dry-stick paper $(1 \times 2 \mathrm{~cm}$; supplied by Oecos Ltd.). The percentage of eggless surface on each corner of dry stick was then estimated in the

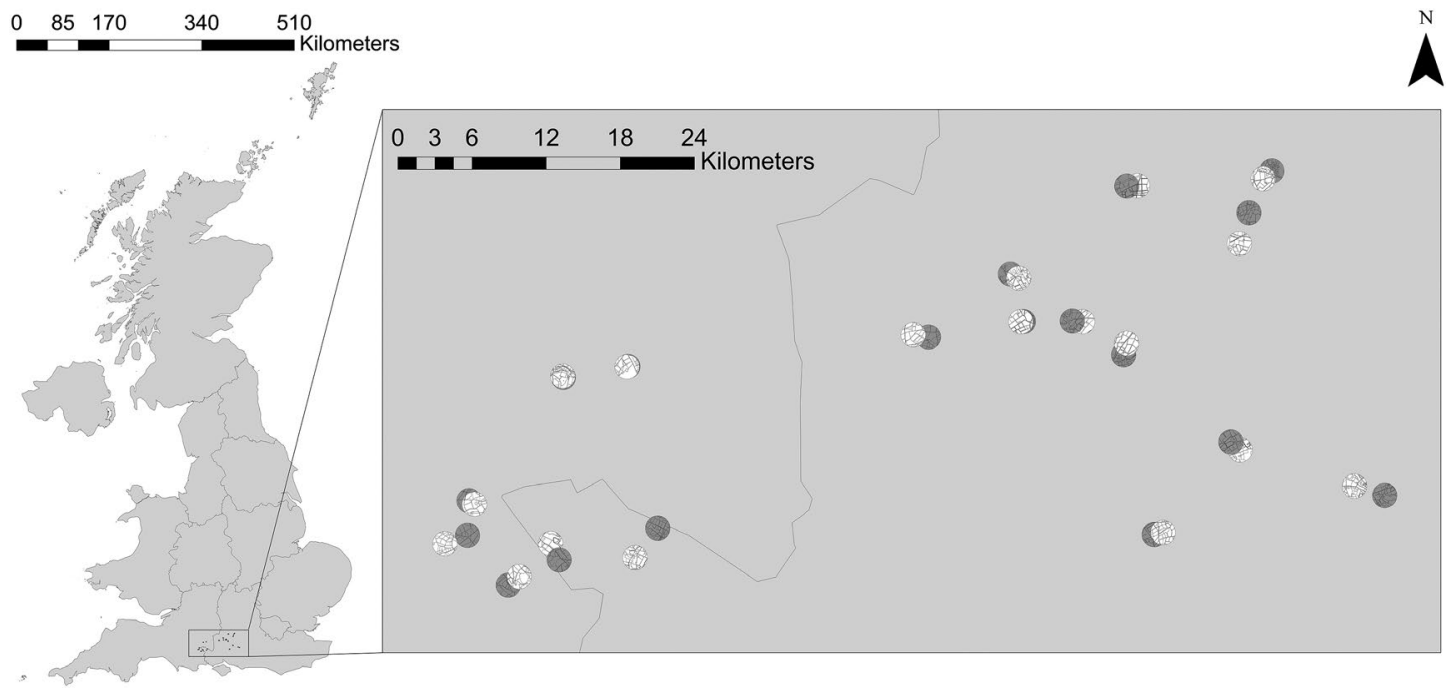

FIGURE 1 Regional map of the UK showing the location of pairs of landscape circles within the South East and South West regions. Dark grey landscape circles were used for experiments in 2014, whereas white landscape circles were used in 2015. Landscapes within each circle were mapped, and removal of six different types of prey was measured in a focal field in each landscape 
laboratory using microscopes). For the seed sentinels, fine sandpaper $(5 \times 10 \mathrm{~cm})$ was attached to plastazote of the same size to provide some rigidity (Westerman et al., 2003). In all, 20 seeds of each species were then attached to the sandpaper using M3 spray mount in two blocks with a $5 \times 4$ arrangement. All other sentinels were attached to dry-stick card which was then coated with fine sand to allow predatory insects to walk across the surface. In total, $10 \mathrm{D}$. melanogaster pupae were attached to dry-stick card and placed on the ground. Ten live adult wingless apterate cereal aphids $S$. avenae were attached to dry-stick card and two cards were stapled onto flag leaves at each sampling point. Natural cereal infestation by aphids was assessed on 25 tillers at each distance along one of the transects, on one occasion in 2014 and two occasions in 2015 when populations would be peaking in both years. All sentinels placed on the ground were covered with a metal cage ( $1 \mathrm{~cm}$ mesh) to prevent access by birds and rodents. Numbers of all sentinels, except for E. kuehniella, were counted when deployed (in case any were lost in transit) and on collection in the field. Assessments were made after $24 \mathrm{hr}$ for animal prey and 7 days for seeds. Seed sentinels were left in the field for longer than animal prey because they are not as perishable as live prey and previous studies recommend that sampling takes place after 2-14 days (Westerman et al., 2003). Partially or totally consumed prey items were recoded as predated.

\section{4 | Analysis}

Data exploration and analysis were conducted in R v.3.2.0 ( $\mathrm{R}$ Core Development Team, 2014). Dotplots together with histograms were used to determine whether transformations of covariates were necessary, and this resulted in rescaling the raw values of the $\mathrm{SNH}$ subcategories and total $\mathrm{SNH}$ prior to analysis using the centring function in the ARM package. Correlations between the rescaled SNH subcategory variables were tested using Pearson correlation coefficients and variance inflation factors (VIFs; leno \& Zuur, 2015). Pearson correlation coefficients showed that correlations were highest between woody areal and herbaceous areal habitats, giving intermediate values between 0.47 and 0.6 (Figures S2-S8); however, VIFs for all other variables were at acceptable levels $(<3$; Table S2); therefore, no variables were excluded from models.

\subsection{1 | Adjacent and habitat area models}

For each sentinel, two models were constructed, one containing total $\mathrm{SNH}$ as an explanatory variable and a second composed of the SNH subcategories-herbaceous linear, herbaceous areal, woody linear and woody areal. Fallow habitats were infrequently recorded and were therefore not included in models. All models accounted for local effects by including the adjacent SNH type and distance of sentinels from that $\mathrm{SNH}$ as fixed effects.

Landscape circle pair was included as a random factor in all models to account for potential variation associated with farm scale factors. Sampling occasion and year were included as either nested random effects or fixed effects, depending on how the model structure influenced model fit. Models with the lowest AIC were selected provided they were not significantly overdispersed, which was tested by calculating the sum of squared Pearson residuals and comparing it to the residual degrees of freedom (Table S3; Zuur \& leno, 2016)

Count data (e.g. P. trivialis seeds) were analysed using the glmer function for generalized mixed effects linear regression with binomial errors, while analyses of continuous response variables (percentage of E. kuehniella eggs predated) were made using the Imer function from the package LME4 for linear mixed effects models with normal error structure (Bates, Maechler, Bolker, \& Walker, 2015). The variable E. kuehniella eggs was $\log (x+1)$ transformed to normalize the data. The model of natural cereal infestation with aphids accounted for infested and uninfested wheat ears, using binomial regression in glmer. Data on S. avenae, P. trivialis seeds and C. album seeds were zero-inflated, $59 \%, 74 \%$ and $72 \%$ of data points were zero, respectively, and the D. melanogaster pupae sentinels experienced $100 \%$ prey removal in $76 \%$ of cases. These response variables were modelled as binary data (presence or absence of predation). Data on C. vomitoria larval data were analysed only for 2014 due to many missing data in 2015. The natural cereal infestation data showed bi-model inflation, it was therefore decided to use the binomial response variable number of tillers infested, number of tillers not infested. The sampling design also resulted in an unbalanced dataset (one sampling round in 2014 and two in 2015) which led to convergence problems, despite testing different model optimizers; to overcome this, the first round of data collected in 2015 was excluded from analysis.

\subsection{2 | Distance-weighted kernel models}

GLMMs were also built to investigate the distance-weighted effect of herbaceous linear, herbaceous areal, woody linear and woody areal habitats on the predation of surrogate prey, where the distance weighting was obtained from the 2Dt-distribution kernel with two parameters, a length scale $u$ in $\mathrm{m}$, and a 'degrees of freedom' or shape parameter $\nu$. Parameters were fitted to the data by maximizing the likelihood (Goedhart, Lof, Bianchi, Baveco, \& van der Werf, 2018; Miguet, Fahrig, \& Lavigne, 2017).

$$
K_{2 \mathrm{Dt}}(r)=\frac{1}{u^{2} \pi v} \frac{\Gamma\left(\frac{v+1}{2}\right)}{\Gamma\left(\frac{v-1}{2}\right)}\left(1+\frac{1}{v} \frac{r^{2}}{u^{2}}\right)^{-\frac{v+1}{2}} .
$$

The 2Dt-distribution is a flexible dispersal model, it can approximate a thin tailed normal distribution $(\nu \rightarrow \infty)$ as well as a fat tailed Cauchy distribution $(\nu \rightarrow 1$ ) enabling high prevalence of long-distance dispersal. The kernel model directly used raster data from the landscape circle in 2014 and 2015 with cells of 2.5 by $2.5 \mathrm{~m}$ to ensure smaller landscape features were preserved. The results from the statistical model (i.e. source strength of the $\mathrm{SNH}$, and length scale of the kernel) can 


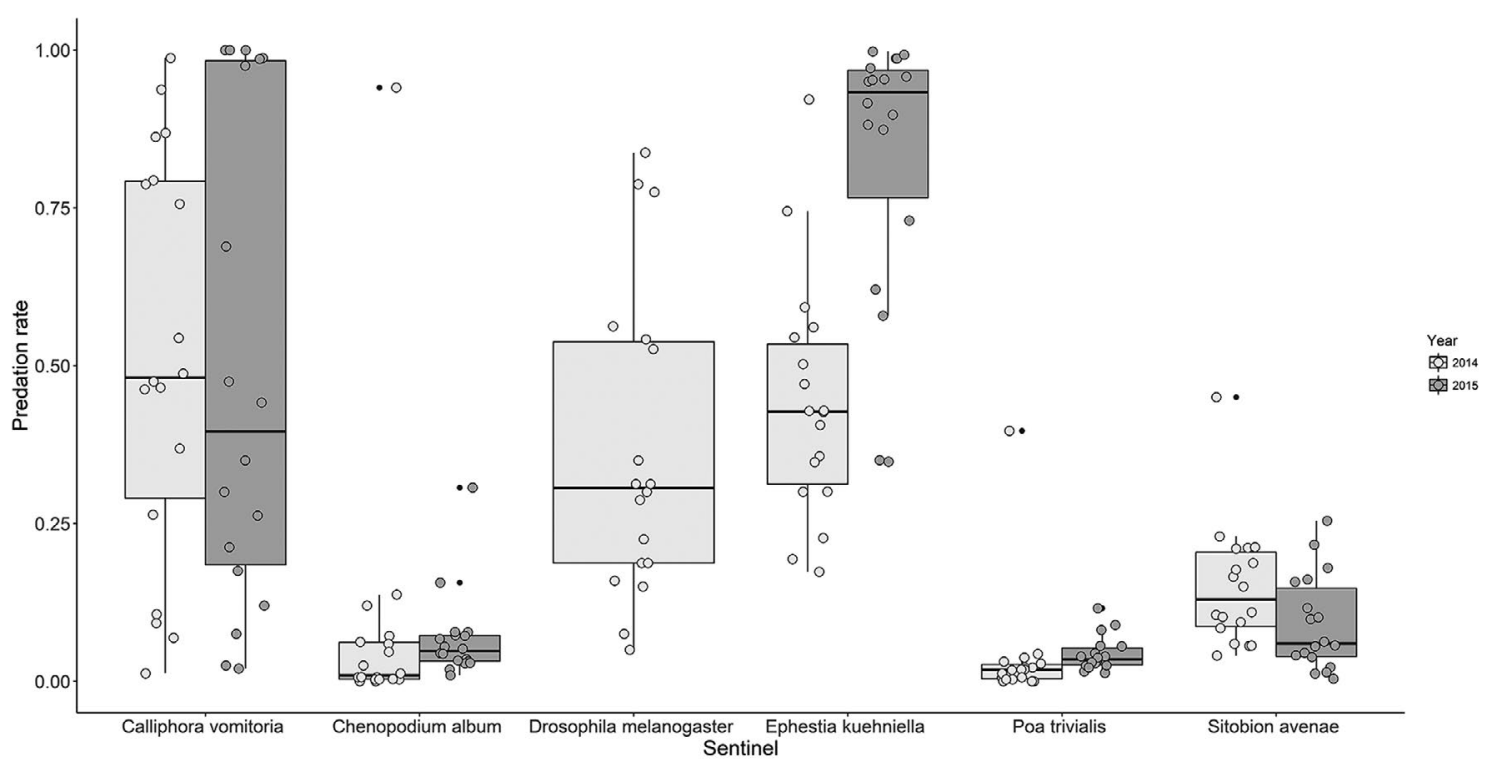

FIGURE 2 Sentinel predation rates showing median (horizontal line), interquartile range (box), solid whisker extending to the upper quartile plus 1.5 times the interquartile range or maximum value if smaller. Predation of Drosophila larvae was monitored in 2014 only. The scatter depicts average predation rates in each landscape circle

therefore be directly used to map potential ecosystem service delivery in the landscape.

Analysis focused on the response variables for predation of C. vomitoria larvae (proportion predated and proportion that were not predated), D. melanogaster pupae (presence or absence of predation), E. kuehniella eggs (percentage predated), adult S. Avenae (presence or absence of predation), $P$. trivialis seeds (presence or absence of predation) and C. album seeds (presence or absence of predation), and natural cereal infestation (infested and uninfested wheat ears), using the same error structure. As above, landscape circle pair was included as a random factor in all models, whereas sampling occasion and year were included as either nested random effects or fixed effects, depending on how the model structure influenced model fit. Adjacent SNH were not included in the kernel models as this is accounted for through the distance weighting of SNH over the whole landscape circle. Model fitting was conducted in $\mathrm{R}$ using a loop to optimize the scale and shape parameters of the kernel model. The spatial scale parameter $u$ was varied between 50 and $500 \mathrm{~m}$ with steps of $10 \mathrm{~m}$ while the shape parameter was set at 25 , since during all test simulations this was the optimal value. For each spatial scale, the model statistics ( $p$ values, Akaike's and information criteria [AIC] Bayesian information criteria $[\mathrm{BIC}]$ and corrected $\mathrm{AICc}$ ) were stored. Final model selection across all kernel-scale parameters was performed by ranking models based on Akaike's information criterion (AIC). The kernel approach was applied using a tailor-made $\mathrm{R}$ script, separately for each sentinel.

\section{3 | RESULTS}

In 2014 and 2015, across landscape circles, the $M( \pm S E)$ percentage cover of arable land was $60.0 \pm 3.2 \%$ and $65.5 \pm 3.2 \%$, respectively, with a minimum coverage of $42.8 \%$ and a maximum of

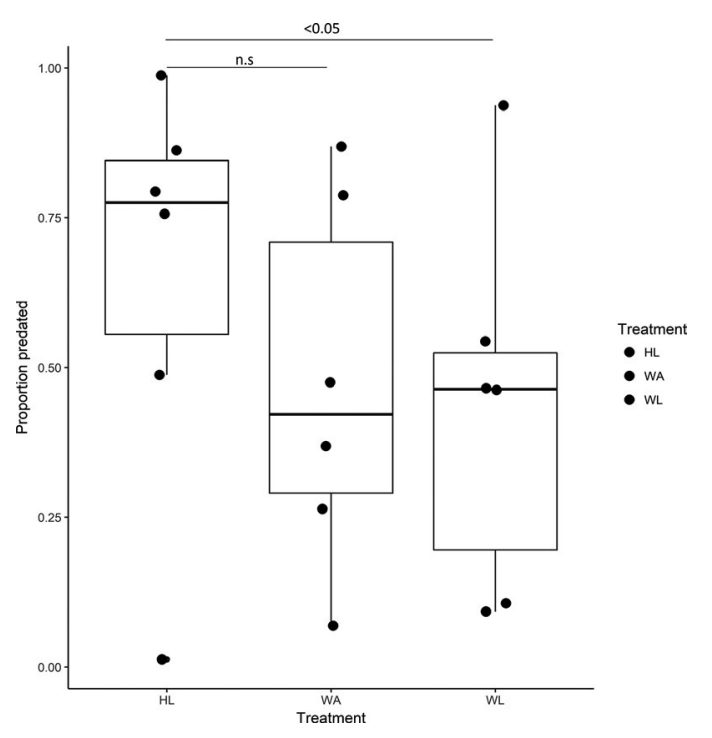

FIGURE 3 Boxplots of Calliphora vomitoria predation rates on transects adjacent to herbaceous linear $(\mathrm{HL})$, woody aereal (WA) and woody linear (WL) semi-natural habitat. Boxplots present the mean quartiles and interquartile range in the conventional style. The scatter depicts the average proportion of $C$. vomitoria predated on transects in each landscape circle

87.1\% (Table S4). Grassland occupied $14.1 \pm 2.3 \%$ and $12.7 \pm 2.5 \%$ of landscape circles in 2014 and 2015, respectively, with a minimum coverage of $0.03 \%$ and a maximum of $36.2 \%$. The overall average SNH landscape circle coverage was $17.1 \pm 3.1 \%$ in 2014 and $14.1 \pm 1.6 \%$ in 2015 , with a minimum cover of $3.0 \%$ and a maximum of $33.9 \%$, of which woody areal typically occupied the largest area (Table S4).

Predation levels and distribution of the data varied considerably between the different sentinel systems with higher mean 
TABLE 1 Output of semi-natural habitats (SNH) types models. Raw values of the SNH subcategories were standardized using the centring function in the ARM package. Estimated slopes $( \pm S E)$, Wald test ( $z$ value) or $T$ test statistic ( $t$ value) and $p$ value significance are given

\begin{tabular}{|c|c|c|c|}
\hline & Estimate $\pm S E$ & $z / t$ & $p$ \\
\hline \multicolumn{4}{|l|}{ Calliphora vomitoria } \\
\hline Intercept (HL adj.) & $0.13 \pm 0.22$ & 0.58 & .55 \\
\hline WA area & $-1.09 \pm 0.35$ & -3.08 & $<.01$ \\
\hline WL area & $-0.46 \pm 0.23$ & -2.03 & $<.05$ \\
\hline HA area & $1.07 \pm 0.34$ & 3.13 & $<.01$ \\
\hline $\mathrm{HL}$ area & $-0.42 \pm 0.25$ & -1.68 & .09 \\
\hline WA adj. & $-0.31 \pm 0.28$ & -1.09 & .27 \\
\hline WL adj. & $-0.77 \pm 0.34$ & -2.23 & $<.05$ \\
\hline Distance & $0.10 \pm 0.04$ & 2.54 & $<.01$ \\
\hline \multicolumn{4}{|l|}{ Drosophila melanogaster } \\
\hline Intercept (HL adj.) & $0.97 \pm 0.66$ & 1.47 & .14 \\
\hline WA area & $-1.46 \pm 0.91$ & -1.61 & .11 \\
\hline WL area & $0.23 \pm 0.51$ & 0.45 & .65 \\
\hline HA area & $2.18 \pm 0.96$ & 2.28 & $<.05$ \\
\hline $\mathrm{HL}$ area & $0.74 \pm 0.58$ & 1.28 & .20 \\
\hline WA adj. & $-0.42 \pm 0.65$ & -0.65 & .52 \\
\hline WL adj. & $-1.08 \pm 0.83$ & -1.23 & .19 \\
\hline Distance & $0.37 \pm 0.19$ & 1.93 & $<.05$ \\
\hline \multicolumn{4}{|l|}{ Ephestia kuehniella } \\
\hline Intercept (HL adj.) & $3.87^{e+00} \pm 2.54^{\mathrm{e}-01}$ & 15.22 & $<.001$ \\
\hline WA area & $1.78^{\mathrm{e}-01} \pm 3.80^{\mathrm{e}-01}$ & 0.49 & .64 \\
\hline $\mathrm{WL}$ area & $9.21^{\mathrm{e}-02} \pm 3.00^{\mathrm{e}-01}$ & 0.31 & .76 \\
\hline HA area & $-1.48^{\mathrm{e}-01} \pm 3.44^{\mathrm{e}-01}$ & -0.43 & .67 \\
\hline $\mathrm{HL}$ area & $-3.25^{\mathrm{e}-02} \pm 3.24^{\mathrm{e}-01}$ & -0.10 & .92 \\
\hline WA adj. & $-3.91^{\mathrm{e}-01} \pm 3.83^{\mathrm{e}-01}$ & -1.02 & .32 \\
\hline WL adj. & $-1.10^{\mathrm{e}-01} \pm 3.74^{\mathrm{e}-01}$ & -0.24 & .77 \\
\hline Distance & $-4.45^{\mathrm{e}-03} \pm 1.58^{\mathrm{e}-02}$ & 0.28 & .78 \\
\hline \multicolumn{4}{|l|}{ Sitobion avenae } \\
\hline Intercept (HL adj.) & $-0.00 \pm 0.27$ & -0.01 & .99 \\
\hline WA area & $-0.20 \pm 0.35$ & -0.58 & .56 \\
\hline WL area & $-0.46 \pm 0.27$ & -1.68 & .09 \\
\hline HA area & $-0.13 \pm 0.32$ & -0.40 & .69 \\
\hline $\mathrm{HL}$ area & $0.62 \pm 0.29$ & 2.10 & $<.05$ \\
\hline WA adj. & $-0.01 \pm 0.35$ & -0.03 & .98 \\
\hline WL adj. & $-0.30 \pm 0.34$ & -0.86 & .39 \\
\hline Distance & $-0.14 \pm 0.06$ & -2.29 & $<.05$ \\
\hline \multicolumn{4}{|l|}{ Poa trivialis } \\
\hline Intercept (HL adj.) & $-2.19 \pm 0.41$ & -5.41 & $<.001$ \\
\hline WA area & $-0.29 \pm 0.49$ & -0.59 & .55 \\
\hline WL area & $-0.04 \pm 0.34$ & -0.11 & .91 \\
\hline HA area & $-0.56 \pm 0.39$ & -1.40 & .16 \\
\hline $\mathrm{HL}$ area & $-0.14 \pm 0.38$ & -0.36 & .72 \\
\hline WA adj. & $0.68 \pm 0.47$ & 1.46 & .15 \\
\hline
\end{tabular}

TABLE 1 (Continued)

\begin{tabular}{lccc}
\hline & Estimate $\pm S E$ & \multicolumn{1}{c}{$z / t$} & $p$ \\
\hline WL adj. & $0.11 \pm 0.43$ & 0.26 & .79 \\
Distance & $0.26 \pm 0.09$ & 2.75 & $<.01$ \\
\hline Chenopodium album & & & \\
Intercept (HL adj.) & $-2.80 \pm 0.47$ & -6.01 & $<.001$ \\
WA area & $-0.86 \pm 0.52$ & 1.64 & .10 \\
WL area & $-0.77 \pm 0.38$ & -2.02 & $<.05$ \\
HA area & $0.23 \pm 0.40$ & 0.58 & .56 \\
HL area & $0.29 \pm 0.39$ & 0.76 & .45 \\
WA adj. & $1.78 \pm 0.52$ & 3.41 & $<.001$ \\
WL adj. & $-0.16 \pm 0.37$ & -0.43 & .67 \\
Distance & $0.25 \pm 0.09$ & 2.76 & $<.01$ \\
Round 2 & $-0.49 \pm 0.21$ & -2.40 & $<.05$ \\
Year 2015 & $1.38 \pm 0.24$ & 5.62 & $<.001$ \\
\hline Natural cereal infestation & & & \\
Intercept (HL adj.) & $-2.08 \pm 0.26$ & -7.91 & $<.001$ \\
WA area & $-0.18 \pm 0.35$ & -0.52 & .61 \\
WL area & $0.35 \pm 0.29$ & 1.20 & .32 \\
HA area & $-0.51 \pm 0.32$ & -1.59 & .11 \\
HL area & $-0.49 \pm 0.39$ & -1.27 & .21 \\
WA adj. & $-0.09 \pm 0.38$ & -0.23 & .82 \\
WL adj. & $1.74 \pm 1.14$ & 1.53 & .13 \\
Distance & $-0.03 \pm 0.04$ & -0.74 & .46 \\
\hline
\end{tabular}

Abbreviations: adj., adjacent; HA, herbaceous areal; HL, herbaceous linear; WA, woody areal; WL, woody linear.

Significant effects are highlighted in bold.

predation for $C$. vomitoria larvae ( $M \pm S E ; 52.8 \pm 2.1 \%$ ), E. kuehniella eggs $(63.2 \pm 1.5 \%)$ and $D$. melanogaster pupae $(36.8 \pm 3.0 \%)$ on the ground, but low levels for $S$. avenae (12.2 $\pm 0.7 \%)$ and with even lower levels for the seeds, $C$. album seeds $(7.6 \pm 0.9 \%)$ and $P$. trivialis seeds $(4.0 \pm 0.5 \%)$ on the ground (Figure 2$)$.

\section{1 | Effects of adjacent habitats and habitat area}

Few effects of the adjacent SNH were found except that predation of $C$. vomitoria larvae (individual SNH model) was almost twice as high in fields bordered by herbaceous linear compared to woody linear habitats ( $p<.05$; Figure 3; Table 1). Chenopodium album seed predation (both models) was higher on transects adjacent to woody areal compared to herbaceous linear habitats $(p<.001$ both models; Tables 1 and 2).

Predation of $C$. vomitoria larvae (total and individual SNH models; $p \leq .01$ both models), D. melanogaster (individual SNH model; $p<.05$ ), and $P$. trivialis and C. album seed predation in total SNH and individual SNH models ( $p<.01$ all four models) increased with distance from the adjacent SNH. In contrast, predation of the sentinel S. avenae (total and individual SNH models $p<.05$ ) decreased with distance from the adjacent SNH (Tables 1 and 2). 
TABLE 2 Output of total semi-natural habitat (SNH) models. Raw values of the SNH were standardized using the centring function in the ARM package. The estimated slope $( \pm S E)$, Wald test statistic ( $z$ value) or $T$ test statistic ( $t$ value) and $p$ value significance are given. (notation as in Table 1)

\begin{tabular}{|c|c|c|c|}
\hline & Estimate $\pm S E$ & $z / t$-val. & $p$ \\
\hline \multicolumn{4}{|l|}{ Calliphora vomitoria } \\
\hline Intercept (HL adj.) & $0.06 \pm 0.29$ & 0.22 & .83 \\
\hline $\mathrm{SNH}$ area & $-0.46 \pm 0.33$ & -1.42 & .16 \\
\hline WA adj. & $-0.42 \pm 0.39$ & -1.08 & .28 \\
\hline WL adj. & $-0.44 \pm 0.38$ & -1.14 & .25 \\
\hline Distance & $0.09 \pm 0.04$ & 2.51 & .01 \\
\hline \multicolumn{4}{|c|}{ Drosophila melanogaster } \\
\hline Intercept (HL adj.) & $0.54 \pm 0.67$ & 0.80 & .42 \\
\hline $\mathrm{SNH}$ area & $0.37 \pm 0.63$ & 0.59 & .55 \\
\hline WA adj. & $-0.57 \pm 0.72$ & -0.80 & .42 \\
\hline WL adj. & $0.27 \pm 0.72$ & 1.91 & .71 \\
\hline Distance & $0.37 \pm 0.19$ & 1.91 & .06 \\
\hline \multicolumn{4}{|l|}{ Ephestia kuehniella } \\
\hline Intercept (HL adj.) & $3.86^{\mathrm{e}+00} \pm 2.41^{\mathrm{e}-01}$ & 15.97 & $<.001$ \\
\hline SNH area & $2.56^{\mathrm{e}+02} \pm 2.87^{\mathrm{e}-01}$ & 0.89 & -.93 \\
\hline WA adj. & $-3.20^{\mathrm{e}-01} \pm 3.50^{\mathrm{e}-01}$ & -0.91 & .37 \\
\hline WL adj. & $-1.43^{\mathrm{e}-01} \pm 3.31^{\mathrm{e}-01}$ & -0.43 & .67 \\
\hline Distance & $4.45^{\mathrm{e}-03} \pm 1.58^{\mathrm{e}-02}$ & 0.28 & .78 \\
\hline \multicolumn{4}{|l|}{ Sitobion avenae } \\
\hline Intercept (HL adj.) & $-0.21 \pm 0.29$ & -0.72 & .47 \\
\hline $\mathrm{SNH}$ area & $-0.06 \pm 0.30$ & -0.20 & .84 \\
\hline WA adj. & $-0.11 \pm 0.36$ & -0.31 & .76 \\
\hline WL adj. & $-0.09 \pm 0.34$ & -0.27 & .79 \\
\hline Distance & $-0.13 \pm 0.06$ & -2.26 & $<.05$ \\
\hline \multicolumn{4}{|l|}{ Poa trivialis } \\
\hline Intercept (HL adj.) & $-2.24 \pm 0.41$ & -5.43 & $<.001$ \\
\hline $\mathrm{SNH}$ area & $-0.76 \pm 0.43$ & -1.76 & .07 \\
\hline WA adj. & $0.85 \pm 0.46$ & 1.86 & .06 \\
\hline WL adj. & $0.09 \pm 0.42$ & 0.21 & .84 \\
\hline Distance & $0.26 \pm 0.09$ & 2.75 & $<.01$ \\
\hline \multicolumn{4}{|l|}{ Chenopodium album } \\
\hline Intercept (HL adj.) & $-2.65 \pm 0.45$ & -5.85 & $<.001$ \\
\hline SNH area & $-0.60 \pm 0.46$ & -1.30 & .19 \\
\hline WA adj. & $1.64 \pm 0.49$ & 3.35 & $<.001$ \\
\hline WL adj. & $-0.22 \pm 0.38$ & -0.58 & .56 \\
\hline Distance & $0.26 \pm 0.09$ & 2.76 & $<.01$ \\
\hline Round 2 & $-0.50 \pm 0.21$ & -2.41 & $<.05$ \\
\hline Year 2015 & $1.23 \pm 0.22$ & 5.55 & $<.001$ \\
\hline \multicolumn{4}{|c|}{ Natural cereal infestation } \\
\hline Intercept (HL adj.) & $-2.13 \pm 0.27$ & -7.81 & $<.001$ \\
\hline $\mathrm{SNH}$ area & $-0.69 \pm 0.32$ & -2.13 & $<.05$ \\
\hline WA adj. & $0.13 \pm 0.37$ & 0.36 & .72 \\
\hline WL adj. & $1.01 \pm 0.84$ & 1.21 & .23 \\
\hline Distance & $-0.03 \pm 0.04$ & -0.73 & .46 \\
\hline
\end{tabular}

Significant effects are highlighted in bold.

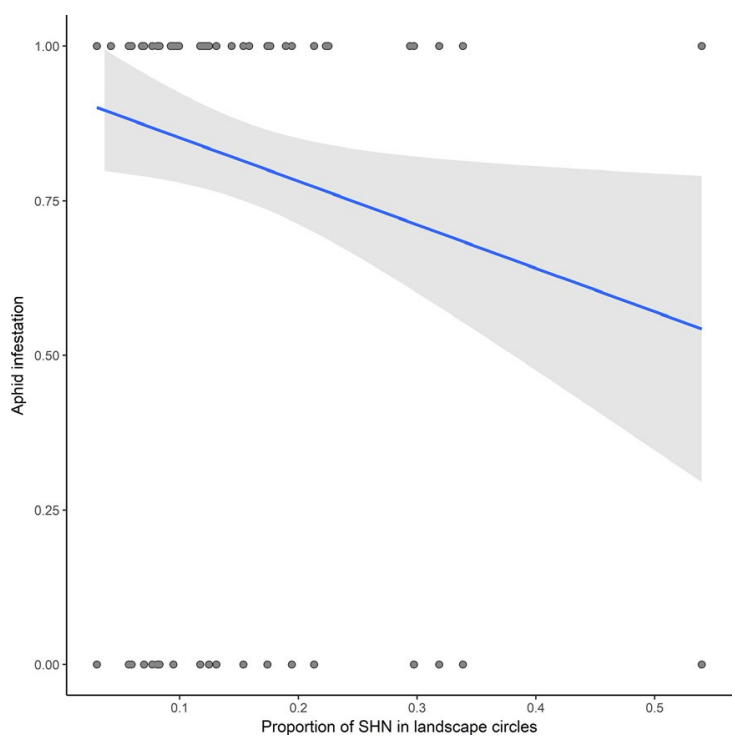

FIGURE 4 Relationship between incidence of cereal aphids and the proportion of semi-natural habitats $(\mathrm{SNH})$ present in landscape circles. The regression line is indicated in blue with its $95 \%$ confidence interval in light grey

The proportion of herbaceous areal habitat in landscape circles had a positive effect on the level of predation on $C$. vomitoria larvae and D. melanogaster pupae ( $p<.01$ both models; Table 1). On the other hand, the proportion of woody linear habitat had a negative effect on $C$. vomitoria larvae and $C$. album seed predation $(p<.05$ both models; Table 1). Similarly, woody areal habitats had a negative effect on $C$. vomitoria larvae predation. Herbaceous linear habitats had a positive impact on S. avenae sentinel predation $(p<.05$; Table 1). The total area of SNH in the landscape circle had a negative effect on natural cereal aphid infestations; in other words, landscape circles with more SNH led to fewer aphids in wheat $(<0.05$; Table 2; Figure 4).

\subsection{Effects of distance-weighted SNH}

Distance-weighted woody areal habitats had a positive effect on C. vomitoria larvae predation and C. album seed predation; however, for C. album, increased seed predation was mainly found on a short scale (close to the woody areas), whereas for C. vomitoria increased larvae predation was found on a large scale (affecting the whole landscape circle; Table 3). Two SNH types affected predation of live $S$. avenae, herbaceous linear habitat in the landscape increased predation, while woody linear habitat in the landscape reduced it (Table 3; Figure 5). Herbaceous areal habitats had a positive effect on predation of $D$. melanogaster pupae but also had a significant effect on natural cereal aphid infestation, landscape circles with more herbaceous areal habitat coverage led to higher aphid infestations (Table 3; Figure 5). Indicating there is a trade-off between increased pest control on the one hand (service) and increased infestation with aphids 
TAB LE 3 Key habitats that affected predation rates on sentinel prey and natural cereal aphid infestations. Habitats marked in green increase predation rate (service), habitats marked in red decrease predation rate (disservice) or increase infestation rate (disservice). $u$ is the spatial scale parameter of the 2Dt-distribution kernel (Section 2.4.2). Estimates are given at the logit scale. The intercept sets the base level of predation, a negative value would result in predation rates between 0 and 0.5 , zero would result in a predation rate of exactly 0.5 ( $50 \%$ predation), and positive values would result in predation rates bigger than 0.5 (up to 1). Negative effect sizes (of either the SNH or the distance) lower the predation/natural infestation rates, whereas positive effect sizes increase the predation rates/natural infestation rate. NA denotes that the effect could not be estimated as there were data for only one sampling occasion or 1 year

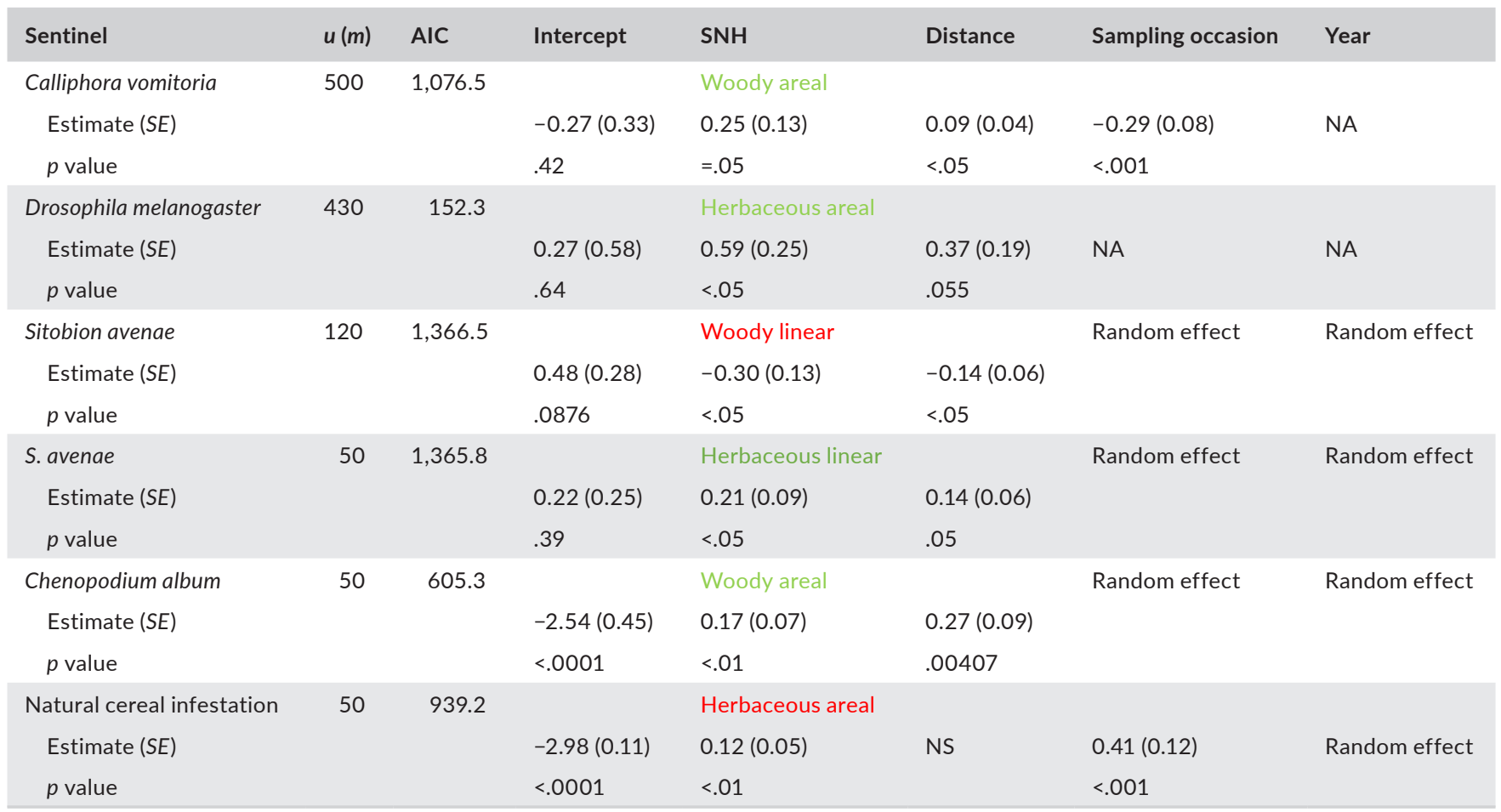

(disservice). Again, there was a difference in the length scale at which the effect occurred, the negative effect on natural cereal infestation was on a short scale (more infestation close to the herbaceous areas), while the positive effect on predation on D. melanogaster pupea was on a large scale, that is, increased predation in the whole landscape circle (Figure 5).

\section{4 | DISCUSSION}

In the study presented here, we provide a unique assessment of the consistency of the effects of semi-natural habitats on six different prey sentinels across a landscape gradient. All sentinels under investigation were predated to some extent, demonstrating that there is potential for biological control in wheat crops, but there was considerable variation in predation rates both between the different types of sentinels and between landscape circles. With all sentinels, there was sometimes $100 \%$ prey removal indicating high potential for biological control. Predation and landscape effects differed depending on the type of sentinel used because landscape will affect different trophic and functional groups of invertebrate natural enemies differently (e.g. Lucas \& Maisonhaute, 2015; Maisonhaute \& Lucas, 2011; Purtauf, Dauber, \& Wolters, 2005).
Predation of insect prey sentinels on the ground was considerably higher for those on the crop or for those comprised of seeds. Occasional observations of predators on the sentinels and use of cameras in the UK and by other project partners revealed that the carnivorous and granivorous predators responsible were usually Carabidae, Staphylinidae and Araneae. Slugs were also observed, especially on the E. kuehniella eggs. Ground sentinels were therefore most likely measuring opportunistic predation events by generalist predators rather than pest-specific ones. Such predation contributes to biological control, especially for cereal aphids which frequently fall off the crop (Winder, 1990) and for those pests that drop to the ground to pupate in the soil (e.g. dipteran pests; Holland \& Thomas, 2000). Identifying the natural enemies responsible is essential if SNH management prescriptions targeted at specific taxa are to be developed and video analysis offers a relatively simple way of confirming this (Zou et al., 2017).

For the sentinels on the crop, mean levels of predation were only $12.2 \%$. It is possible that the aphid sentinel used here underestimated control by their most important and effective predators, flying natural enemies which largely comprise predatory Diptera, Coleoptera and Linyphiidae (Araneae; Holland et al., 2012). We offer some possible explanations for this. For aphid sentinels, control is typically provided by pest-specific natural enemies using chemical cues to detect colonies, such as honeydew (Carter \& 

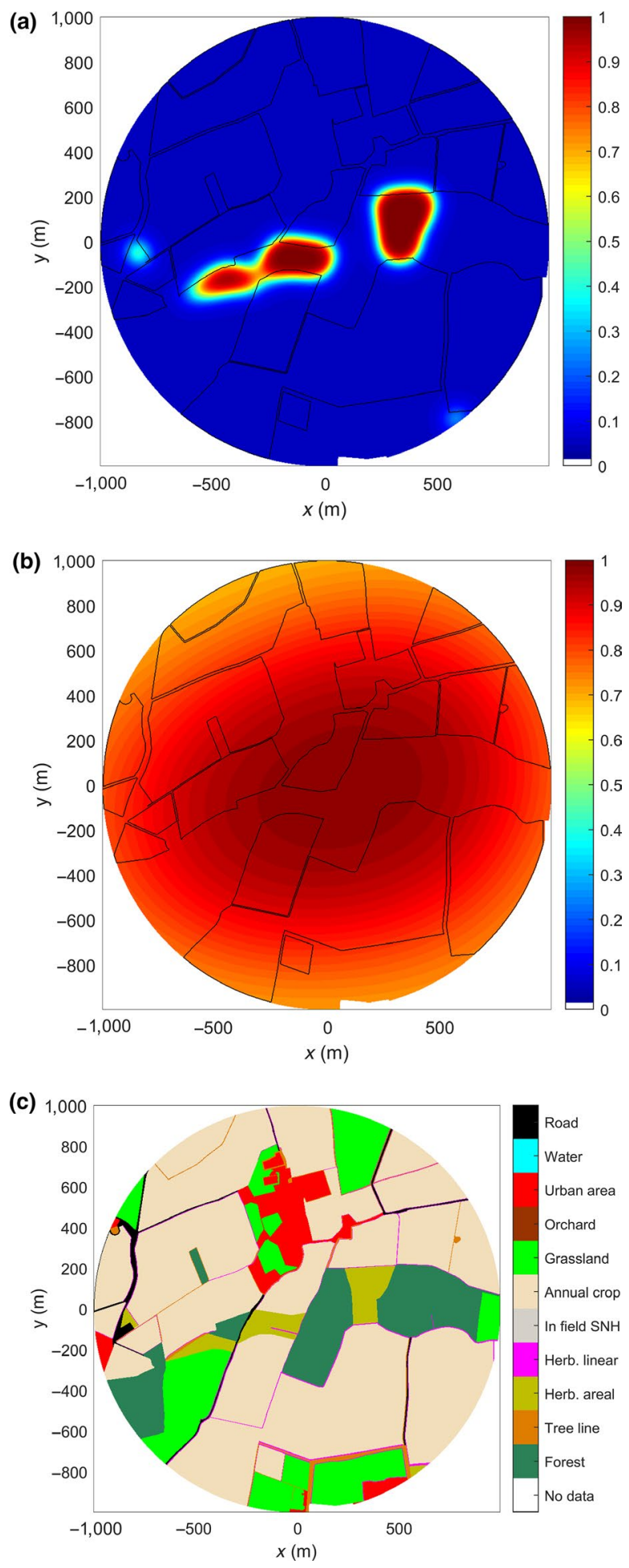

FIGURE 5 Spatial effect of herbaceous areal habitats on (a) natural infestation by cereal aphids (fraction infested) and (b) predation of Drosophila melanogaster pupea (fraction predated). Black contours mark borders of annual crop fields. Fraction infested and fraction predated are calculated with 2Dt-distribution kernel in Section 2.4.2 parameterized with the values for the optimal model presented in Table 3. The scales on the right-hand side of (a) and (b) are the predicted predation rates in the landscape, ranging from 0 to 1 (0\%-100\% predation), based on the distribution of herbaceous areal habitats in the landscape. Panel (c) depicts the main habitats in the 1-km landscape circle
Dixon, 1984), although hoverfly larvae detected aphids even when crushed (Francis, Martin, Lognay, \& Haubruge, 2005). As the aphids attached to dry-stick cards were not feeding, this cue would be missing. In addition, the natural enemies may require a minimum colony size for detection. The natural enemies may have also been discouraged by the cards themselves. Zou et al. (2017) found when using brown plant hoppers (Nilopervata lugens) as a sentinel in rice that live hoppers gave different rates of predation than immobilized hoppers. Furthermore, camera observations showed that different groups of carnivores attacked the dead, live immobile and live mobile prey (Zou et al., 2017). Despite the caveats however, sentinels remain a useful method for measuring biological control.

There were relatively few effects of the adjacent habitat, but if they occurred they were both positive and negative depending on the sentinel and habitat type. If the adjacent boundary was an herbaceous linear strip, then greater predation of $C$. vomitoria larvae occurred compared to where there was a woody linear habitat. Similarly, predation of $S$. Avenae sentinels increased in landscape circles with high herbaceous linear habitat coverage and our distance-weighted model showed that this effect was significant at a short length scale; therefore, herbaceous linear habitats are most likely to benefit biocontrol of $S$. Avenae when located adjacent infested areas, this may be particularly important if fields are bordered by woody liner habitats as they were associated with decreased S. Avenae predation. These results provide further evidence that farmers can introduce linear herbaceous features to benefit biological control, the mechanism being that many species of Carabidae and Staphylinidae overwinter under tussock forming grasses (Sotherton, 1984) and higher densities are more likely to occur in herbaceous linear habitats than hedgerow (Griffiths, Winder, Holland, Thomas, \& Williams, 2007). In the spring, these beetles migrate into the crops (Collins, Boatman, Wilcox, \& Holland, 2002; Coombes \& Sotherton, 1986) and, if these were responsible for sentinel predation, it may explain the differences. In contrast, predation of $C$. album seeds was higher next to woodland compared to herbaceous linear strips, which may mean that woodland supports more spermophagous beetles that spill-over into the crop or that woodland is a less attractive habitat for field overwintering species. The recommendation for farmers suffering from infestations of seed predators, and wishing to improve biocontrol, would be to plant up woodland adjacent to problem fields.

The mean levels of seed predation were very low (4\% or $7 \%$ ) compared to that of the insect prey despite being left out for longer. Carabid beetles are the most likely predators in arable crops, but only a few species are capable of consuming seeds and typically are less abundant than more generalist species (Tooley \& Brust, 2002). However, higher levels were found in some landscape circles reflecting landscape scale variation in species composition (Jonason, Smith, Bengtsson, \& Birkhofer, 2013). Such heterogeneity may reflect movement to more favourable crops, such as oilseed rape which has higher seed abundance. Indeed, positive relationships have been found between carabid abundance and landscapes with more grassland and oilseed rape (Trichard et al., 2013). Seeds are predated by a wider range of organisms than insects (Westerman et al., 2003), but 
in this study the mostly likely candidates were field overwintering beetles since seeds were more likely to be predated with increasing distance from the field edge. This pattern of predation was also recorded in C. vomitoria and D. melanogaster larvae sentinels.

One-kilometre landscape scale analysis of $C$. vomitoria larvae and D. melanogaster pupae showed that high coverage of herbaceous areal habitats would benefit farming by enhancing biocontrol. When natural cereal aphid infestations were measured, no effects of adjacent habitats were identified; however, kernel analysis revealed that the presence of local herbaceous areal habitats had a larger impact on increased infestation rates while having more $\mathrm{SNH}$ per se in the $1-\mathrm{km}$ landscape reduced infestations. Numerous studies have also identified positive relationships between the percentage non-crop area and/or negative effects of percentage crop area in the surrounding landscapes on aphid abundance and primary parasitism in crops (e.g. Martin, Reineking, Seo, \& Steffan-Dewenter, 2013), but these studies do not disentangle the effects of individual SNH in the landscapes. Where SNH types were considered, the proportion of grassland had no impact on cereal aphids or natural enemies, but shrubland had a positive effect on aphid abundance in wheat (Jankovic et al., 2017), whereas the area of grassland and vegetation strips correlated positively with aphid abundance (Meyhöfer, Klug, \& Poehling, 2008). Increased coverage of forest and $\mathrm{SNH}$ as an aggregated category also correlated with decreasing aphid abundance (Meyhöfer et al., 2008).

The seed sentinel C. album also showed local, landscape and distance-weighted responses. Opposing effects were detected in relation to woody habitats, with woody areal habitats proving beneficial at the local scale and woody linear negative at the 1-km landscape scale. Some spermophagous carabids (e.g. Amara plebja) overwinter in woodland, flying into crops in spring (van Huizen, 1977) and may explain the benefit of woody areal habitats while carabids were more abundant near to woody linear habitats (Fusser et al., 2018) which may offer more seed food than crops. The kernel distance-weighted model also showed that $C$. vomitoria larvae predation is more strongly influenced by woody areal habitats at a $500 \mathrm{~m}$ scale. The type of cropping that occurs in a landscape also has the potential to influence biological control (Östman, Ekbom, \& Bengtsson, 2001), but to prevent model overparameterization it was not investigated here.

\section{5 | CONCLUSIONS}

In conclusion, the tested sentinel systems were predated by invertebrate natural enemies and were sensitive enough to detect the influence of $\mathrm{SNH}$ at both local and landscape scales. Predation rates varied greatly between different sentinel types, especially between those presented on the soil surface and those presented on the foliage. This means that no single sentinel type is sufficient to measure the pest suppressiveness of the landscape. It is very likely that different sentinels attract different guilds of consumers, hence using multiple sentinels is likely to give a better perspective on predation intensity than using just a single sentinel. Furthermore, it may be useful to know whether general predation is occuring or if pest-specific natural enemies are responsible, as these may be more effective at preventing outbreaks. Finally, it would be advantageous when developing sentinels to operate them in conjunction with other measures of pest infestation levels or measurement of biocontrol (e.g. exclusion cages) to validate the sentinel (Chisholm et al., 2014) which may also permit scores of biocontrol level to be generated.

\section{ACKNOWLEDGEMENTS}

The sentinel systems and experimental design were developed by the QuESSA partners which received funding from the European Union's Seventh Framework Programme under grant agreement No. 311879. Our thanks to the farmers for allowing us to conduct the studies on their farms, everyone that assisted with the field studies. CLAD contains, or is derived from, information supplied by the Ordnance Survey and Rural Payments Agency. (C) Crown copyright and database rights 2014. Ordnance Survey 100022021. Thanks to Chris Heward for producing a graphical abstract.

\section{AUTHORS' CONTRIBUTIONS}

J.M.H. and W.V.d.W. conceived the experiment; J.M.H. and S.M. collected the data; N.M.M. collated and digitized the data; N.M.M. and M.E.L. analysed the data; N.M.M. and J.M.H. wrote the manuscript. All authors contributed critically to the drafts and approved the manuscript for publication.

\section{DATA AVAILABILITY STATEMENT}

Data available via the Dryad Digital Repository https://doi.org/ 10.5061/dryad.x69p8czf0 (McHugh, Moreby, Lof, Van der Werf, \& Holland, 2020).

ORCID

Niamh M. McHugh (iD https://orcid.org/0000-0001-6659-7266

\section{REFERENCES}

Bates, D., Maechler, M., Bolker, B., \& Walker, S. (2015). Fitting linear mixed-effects models using Ime4. Journal of Statistical Software, 67(1), 1-48. https://doi.org/10.18637/jss.v067.i01

Bianchi, F. J., Booij, C. J. H., \& Tscharntke, T. (2006). Sustainable pest regulation in agricultural landscapes: A review on landscape composition, biodiversity and natural pest control. Proceedings of the Royal Society of London B: Biological Sciences, 273, 1715-1727. https://doi. org/10.1098/rspb.2006.3530

Cardina, J., \& Sparrow, D. H. (1996). A comparison of methods to predict weed seedling populations from the soil seedbank. Weed Science, 44, 46-51. https://doi.org/10.1017/s004317450009353x

Carter, M. C., \& Dixon, A. F. G. (1984). Honeydew: An arrestant stimulus for coccinellids. Ecological Entomology, 9, 383-387. https://doi. org/10.1111/j.1365-2311.1984.tb00834.x

Chisholm, P. J., Gardiner, M. M., Moon, E. G., \& Crowder, D. W. (2014). Tools and techniques for investigating impacts of habitat complexity on biological control. Biological Control, 75, 48-57. https://doi. org/10.1016/j.biocontrol.2014.02.003

Collins, K. L., Boatman, N. D., Wilcox, A., \& Holland, J. M. (2002). The influence of beetle banks on cereal aphid population predation in winter wheat. Agriculture, Ecosystems \& Environment, 93, 337-350. https://doi.org/10.1016/s0167-8809(01)00340-1 
Coombes, D. S., \& Sotherton, N. W. (1986). The dispersion of polyphagous predators from their overwintering sites into cereal fields and factors affecting their distribution in the spring and summer. Annals of Applied Biology, 108, 461-474.

Cromar, H. E., Murphy, S. D., \& Swanton, C. J. (1999). Influence of tillage and crop residue on postdispersal predation of weed seeds. Weed Science, 47(2), 184-194. https://doi.org/10.1017/S0043174500091608

ESRI. (2011). ArcGIS desktop: Release 10. Redlands, CA: Environmental Systems Research Institute.

Francis, F., Martin, T., Lognay, G., \& Haubruge, E. (2005). Role of (E)-betafarnesene in systematic aphid prey location by Episyrphus balteatus larvae (Diptera: Syrphidae). European Journal of Entomology, 102, 431-436. https://doi.org/10.14411/eje.2005.061

Fusser, M. S., Holland, J. M., Jeanneret, P., Pfister, S. C., Entling, M. H., \& Schirmel, J. (2018). Interactive effects of local and landscape factors on farmland carabids. Agricultural and Forest Entomology, 20, 549557. https://doi.org/10.1111/afe.12288

Goedhart, P. W., Lof, M. E., Bianchi, F. J. J. A., Baveco, J. M., \& van der Werf, W. (2018). Estimation of the spatial distribution of mobile agent-based ecosystem services. Methods in Ecology and Evolution, 9, 1241-1249. https://doi.org/10.1111/2041-210X.12972

Griffiths, G. J., Holland, J. M., Bailey, A., \& Thomas, M. B. (2008). Efficacy and economics of shelter habitats for conservation biological control. Biological Control, 45(2), 200-209. https://doi.org/10.1016/ j.biocontrol.2007.09.002

Griffiths, G. J. K., Winder, L., Holland, J. M., Thomas, C. F. G., \& Williams, E. (2007). The representation and functional composition of carabid and staphylinid beetles in different field boundary types at a farm-scale. Biological Conservation, 135, 145-152. https://doi.org/ 10.1016/j.biocon.2006.09.016

Holland, J. M., Bianchi, F. J., Entling, M. H., Moonen, A. C., Smith, B. M., \& Jeanneret, P. (2016). Structure, function and management of semi-natural habitats for conservation biological control: A review of European studies. Pest Management Science, 72(9), 1638-1651. https://doi.org/10.1002/ps.4318

Holland, J. M., Douma, J. C., Crowley, L., James, L., Kor, L., Stevenson, D. R., \& Smith, B. M. (2017). Semi-natural habitats support biological control, pollination and soil conservation in Europe. A review. Agronomy for Sustainable Development, 37, 31. https://doi.org/ 10.1007/s13593-017-0434-x

Holland, J. M., Oaten, H., Moreby, S., Birkett, T., Simper, J., Southway, S., \& Smith, B. M. (2012). Agri-environment scheme enhancing ecosystem services: A demonstration of improved biological control in cereal crops. Agriculture, Ecosystems \& Environment, 155, 147-152. https://doi.org/10.1016/j.agee.2012.04.014

Holland, J. M., Storkey, J., Lutman, P. J. W., Birkett, T. C., Simper, J., \& Aebischer, N. J. (2014). Utilisation of agri-environment scheme habitats to enhance invertebrate ecosystem service providers. Agriculture, Ecosystems \& Environment, 183, 103-109. https://doi.org/10.1016/ j.agee.2013.10.025

Holland, J. M., \& Thomas, S. R. (2000). Do polyphagous predators help control orange wheat blossom midge, Sitodiplosis mosellana Gehin (Dipt., Cecidomyiidae) in winter wheat? Journal of Applied Entomology, 124(7-8), 325-330. https://doi.org/10.1046/j.1439-0418.2000.00478.x

leno, E. N., \& Zuur, A. F. (2015). A Beginner's guide to data exploration and visualisation with R. Newburgh, UK: Highland Statistics Limited.

Jankovic, M., Plecas, M., Sandic, D., Popovic, A., Petrovic, A., PetrovicObradovic, O., ... Gagic, V. (2017). Functional role of different habitat types at local and landscape scales for aphids and their natural enemies. Journal of Pest Science, 90, 261-273. https://doi.org/10.1007/ s10340-016-0744-9

Jonason, D., Smith, H. G., Bengtsson, J., \& Birkhofer, K. (2013). Landscape simplification promotes weed seed predation by carabid beetles (Coleoptera: Carabidae). Landscape Ecology, 28, 487. https://doi.org/ 10.1007/s10980-013-9848-2
Kottek, M., Grieser, J., Beck, C., Rudolf, B., \& Rubel, F. (2006). World map of the Köppen-Geiger climate classification updated. Meteorologische Zeitschrift, 15(3), 259-263.

Lucas, É., \& Maisonhaute, J. É. (2015). Differential responses of granivorous, ominivorous and carnivorous species of ground beetles (Coleoptera: Carabidae) to local and landscape characteristics in a Canadian landscape. Acta Societatis Zoologicae Bohemicae, 79, 83-94.

Maisonhaute, J. É., \& Lucas, É. (2011). Influence of landscape structure on the functional groups of an aphidophagous guild: Active-searching predators, furtive predators and parasitoids. European Journal of Environmental Sciences, 1, 41-50. https://doi.org/10.14712/23361964.2015.64

Martin, E. A., Reineking, B., Seo, B., \& Steffan-Dewenter, I. (2013). Natural enemy interactions constrain pest control in complex agricultural landscapes. Proceedings of the National Academy of Sciences of the United States of America, 110(14), 5534-5539. https://doi.org/ 10.1073/pnas.1215725110

McHugh, N. M., Moreby, S., Lof, M. E., Van der Werf, W., \& Holland, J. M. (2020). Data from: The contribution of semi-natural habitats to biological control is dependent on sentinel prey type. Dryad Digital Repository, https://doi.org/10.5061/dryad.x69p8czf0

Meyhöfer, R., Klug, T., \& Poehling, H. M. (2008). Are landscape structures important for the colonization of spinach fields by insects? IOBC/ wprs Bulletin, 34, 69-72.

Miguet, P., Fahrig, L., \& Lavigne, C. (2017). How to quantify a distance-dependent landscape effect on a biological response. Methods in Ecology and Evolution, 8(12), 1717-1724. https://doi.org/ 10.1111/2041-210X.12830

Östman, Ö., Ekbom, B., \& Bengtsson, J. (2001). Landscape heterogeneity and farming practice influence biological control. Basic and Applied Ecology, 2(4), 365-371. https://doi.org/10.1078/1439-1791-00072

Purtauf, T., Dauber, J., \& Wolters, W. (2005). The response of carabids to landscape simplification differs between trophic groups. Oecologia, 142, 458-464. https://doi.org/10.1007/s00442-004-1740-y

R Core Development Team. (2014). R: A language and environment for statistical computing. Vienna, Austria: R Foundation for Statistical Computing.

Rusch, A., Chaplin-Kramer, R., Gardiner, M. M., Hawro, V., Holland, J., Landis, D., ... Bommarco, R. (2016). Agricultural landscape simplification reduces natural pest control: A quantitative synthesis. Agriculture, Ecosystems \& Environment, 221, 198-204. https://doi.org/ 10.1016/j.agee.2016.01.039

Sotherton, N. W. (1984). The distribution and abundance of predatory arthropods overwintering on farmland. Annals of Applied Biology, 105(3), 423-429. https://doi.org/10.1111/j.1744-7348.1984.tb03068.x

Thorbek, P., \& Topping, C. J. (2005). The influence of landscape diversity and heterogeneity on spatial dynamics of agrobiont linyphiid spiders: An individual-based model. BioControl, 50(1), 1-33. https://doi. org/10.1007/s10526-004-1114-8

Tooley, J., \& Brust, G. E. (2002). Weed seed predation by carabid beetles. In J. M. Holland (Ed.), The agroecology of carabid beetles (pp. 215-230). Andover, UK: Intercept.

Trichard, A., Alignier, A., Biju-Duval, L., \& Petit, S. (2013). The relative effects of local management and landscape context on weed seed predation and carabid functional groups. Basic and Applied Ecology, 14(3), 235-245. https://doi.org/10.1016/j.baae.2013.02.002

Tscharntke, T., Tylianakis, J. M., Rand, T. A., Didham, R. K., Fahrig, L., Batáry, P., ... Westphal, C. (2012). Landscape moderation of biodiversity patterns and processes-eight hypotheses. Biological Reviews, 87(3), 661-685. https://doi.org/10.1111/j.1469-185X.2011. 00216.x

van Huizen, T. H. P. (1977). The significance of flight activity in the life cycle of Amara plebeja Gyll. (Coleoptera, Carabidae). Oecologia, 29, 358. https://doi.org/10.1007/BF00345809

Westerman, P. R., Hofman, A., Vet, L. E. M., \& van der Werf, W. (2003). Relative importance of vertebrates and invertebrates in epigeaic 
weed seed predation in organic cereal fields. Agriculture, Ecosystems \& Environment, 95(2-3), 417-425. https://doi.org/10.1016/S01678809(02)00224-4

Winder, L. (1990). Predation of the cereal aphid Sitobion avenae by polyphagous predators on the ground. Ecological Entomology, 15(1), 105-110. https://doi.org/10.1111/j.1365-2311.1990.tb00789.x

Zou, Y., de Kraker, J., Bianchi, F. J. J. A., van Telgen, M. D., Xiao, H. J., $\&$ van der Werf, W. (2017). Video monitoring of brown planthopper predation in rice shows flaws of sentinel methods. Scientific Reports, 7, 42210. https://doi.org/10.1038/srep42210

Zuur, A. F., \& leno, E. N. (2016). A protocol for conducting and presenting results of regression-type analyses. Methods in Ecology and Evolution, 7(6), 636-645. https://doi.org/10.1111/2041-210X.12577

\section{SUPPORTING INFORMATION}

Additional supporting information may be found online in the Supporting Information section.

How to cite this article: McHugh NM, Moreby S, Lof ME, Van der Werf W, Holland JM. The contribution of semi-natural habitats to biological control is dependent on sentinel prey type. J Appl Ecol. 2020;57:914-925. https://doi.org/10.1111/13652664.13596 